\title{
Deoxyguanosine Triphosphate as a Possible Toxic Metabolite in the Immunodeficiency Associated with Purine Nucleoside Phosphorylase Deficiency
}

\author{
amos Cohen, Lorraine J. Gudas, Arthur J. Ammann, Gerard E. J. Staal, \\ and David W. Martin, JR., Departments of Medicine, Biochemistry and \\ Biophysics, and Pediatrics, University of California at San Francisco, \\ San Francisco, California 94143, and the Department of Medical Enzymology, \\ Academic Hospital, Utrecht, The Netherlands
}

A B S T RACT Purine nucleoside phosphorylase (PNP) deficiency is associated with a severe defect in thymus-derived (T)-lymphocyte function combined with normal bone marrow-derived (B)-lymphocyte function. To investigate the role of this enzyme deficiency in the resulting immune dysfunction, we measured the levels of ribonucleoside and deoxyribonucleoside triphosphates in erythrocytes from two unrelated PNP-deficient, T-lymphocyte-deficient patients. Both PNP-deficient patients have abnormally high levels of deoxyguanosine triphosphate (deoxyGTP) in their erythrocytes ( 5 and $8 \mathrm{nmol} / \mathrm{ml}$ packed erythrocytes). In contrast, normal controls and adenosine deaminase-deficient, immunodeficient patients do not have detectable amounts of deoxyGTP $(<0.5$ $\mathrm{nmol} / \mathrm{ml}$ packed erythrocytes). We propose that deoxvguanosine, a substrate of PNP, is the potentially lymphotoxic metabolite in PNP deficiency. The mechanism of toxicity involves phosphorylation of

Dr. Cohen is supported by a Program Project grant, Clinical Pharmacology-Pharmacokinetics, from the National Institutes of Health. Dr. Gudas was supported by a fellowship from the National Institute of Child Health and Human Development. Dr. Martin is an Investigator, Howard Hughes Medical Institute. Reprint requests should be addressed to Dr. Martin at University of California at San Francisco, Department of Medicine, M-1093, San Francisco, Calif. 94143.

Received for publication 27 December 1977 and in revised form 10 February 1978 . deoxyguanosine to deoxyGTP, which acts as a potent inhibitor of mammalian ribonucleotide reductase.

\section{INTRODUCTION}

Deficiencies in either adenosine deaminase $(\mathrm{ADA})^{1}$ or purine nucleoside phosphorylase (PNP), two enzymes which act sequentially in the purine salvage pathway (Fig. 1), are associated with immunodeficiency diseases $(1,2)$. Whereas ADA deficiency results in combined bone marrow-derived (B)- and thymusderived (T)-lymphocyte deficiency, PNP-deficient patients exhibit T-cell dysfunction with normal Blymphocyte function. While there are a number of proposed mechanisms to explain the association of lymphotoxicity with ADA deficiency $(3-7)$, the cause of the T-cell deficiency associated with the absence of PNP activity has received less attention. It was postulated that an accumulation of the PNP substrate, inosine, inhibited ADA activity causing functional ADA deficiency (8). Subsequently, orotic aciduria was found in two PNP-deficient patients,

\footnotetext{
'Abbreviations used in this paper: ADA, adenosine. deaminase; deoxyATP, deoxyadenosine triphosphate; deoxyCTP, deoxycytidine triphosphate; deoxyGTP, deoxyguanosine triphosphate; GTP, guanosine triphosphate; HGPRT, hypoxanthine-guanine phosphoribosyl transferase; HPLC, high-performance liquid chromatography; PNP, purine nucleoside phosphorylase.
} 


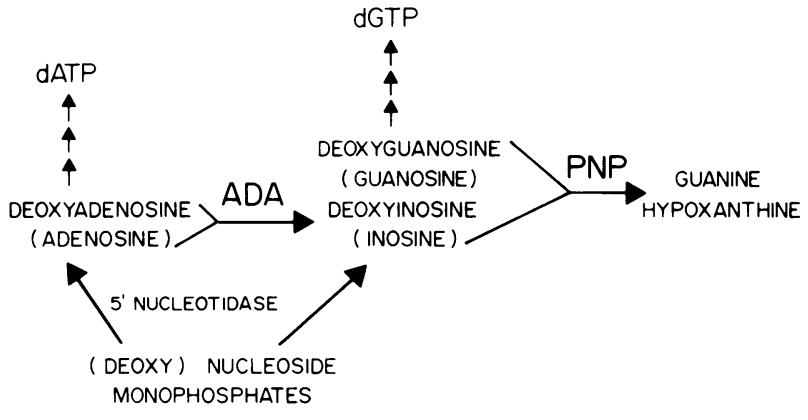

Figure 1 Enzymes involved in purine nucleoside metabolism.

indicating that pyrimidine starvation might exist in some of the tissues of the patients (9). However, oral uridine therapy did not significantly improve their immune function but did eliminate the orotic aciduria (9).

Recently, strikingly high levels of deoxyadenosine triphosphate (deoxyATP) were found in erythrocytes from several ADA-deficient, immunodeficient patients (10). Since deoxyATP is a known inhibitor of ribonucleotide reductase (11), it was suggested that an accumulation of deoxyATP in the patients' lymphocytes is the cause of the immunodeficiency in ADAdeficient children (10).

Deoxyguanosine is one of the four PNP substrates which accumulate in the urine of PNP-deficient children (12). Human lymphocytes are capable of phosphorylating deoxyguanosine to deoxyguanosine triphosphate (deoxyGTP) (13), which like deoxyATP can inhibit mammalian ribonucleotide reductase (11).

Thus, we measured deoxyGTP levels in erythrocytes from PNP-deficient patients and normal controls, and we now demonstrate that deoxyGTP is present in erythrocytes from PNP-deficient patients but not in normal control erythrocytes.

\section{METHODS}

Materials. Nucleotide and deoxynucleotide standards were purchased from Sigma Chemical Co., St. Louis, Mo. DNA-dependent DNA plymerase and calf thymus DNA were purchased from Miles Laboratories Inc., Elkhart, Ind. $\left[{ }^{3} \mathrm{H}\right] \mathrm{TTP} \quad(60 \mathrm{Ci} / \mathrm{mmol})$ was purchased from New England Nuclear, Boston, Mass. All other reagents were of the highest grades commercially available.

Patients. The two immunodeficient children, patient $1(2)$ and patient 2 (14), with inherited deficiencies of PNP have been previously described. The ADA-deficient child with combined B- and T-lymphocyte deficiency has also been described previously (10) as has the adult male deficient in erythrocyte hypoxanthine-guanine phosphoribosyl transferase (HGPRT) (12). The control subjects included normal children and adults and two immunodeficient children. One immunodeficient child has a severe combined immunodeficiency while the other has only a $\mathrm{T}$ lymphocyte deficiency, but both children have normal activities of ADA and PNP in their erythrocytes. None of the immunodeficient patients had been transfused or was receiving drugs before study.

Preparation of samples. Whole blood $(2-3 \mathrm{ml})$ was withdrawn from patients into heparinized svringes and promptly centrifuged $(10,000 \mathrm{~g}$ for $2 \mathrm{~min})$ at ambient temperature. The plasma was removed, and an equal volume of ice-cold $2 \mathrm{~N}$ perchloric acid was added to the erythrocyte pellet. The chilled mixture was again centrifuged $(10,000 \mathrm{~g}$ for $2 \mathrm{~min})$ to remove the precipitated protein, and the supernate was neutralized to pH 6 to 8 with $5 \mathrm{~N} \mathrm{KOH}$, to precipitate potassium perchlorate. After chilling on ice, the supernatant solutions were centrifuged to remove the potassium perchlorate, frozen, and when necessary, shipped to San Francisco, Calif. for analysis.

High performance liquid chromatography. High performance liquid chromatography was performed utilizing an Altex metering system with a $20-\mu \mathrm{l}$ UV analyzer (Altex Scientific Inc., Berkeley, Calif.), as described previously (10).

Enzymatic determination of deoxyGTP. The concentration of deoxyGTP in erythrocyte extracts was determined by the method of Solter and Handschumacher (15), utilizing the dependence of the DNA polymerase reaction upon the presence of the triphosphates of all four deoxyribonucleosides. The reactions were carried out for $60 \mathrm{~min}$ in the presence of saturating amounts of deoxycytidine triphosphate (deoxyCTP) $(2 \mu \mathrm{M})$, deoxyATP $(2 \mu \mathrm{M})$ and $\left[{ }^{3} \mathrm{H}\right] \mathrm{TTP}$ $(0.6 \mu \mathrm{Ci}, 2 \mu \mathrm{M})$. The reaction was dependent upon, and linear with, the volume of added erythrocyte extract. deoxyGTP standards added to normal erythrocyte extracts could not be detected at concentrations corresponding to less than 0.5 $\mathrm{nmol} / \mathrm{ml}$ of packed erythrocytes.

\section{RESULTS}

The levels of nucleoside triphosphates in erythrocyte extracts from ADA- and PNP-deficient patients, and from normal controls, were determined with highperformance liquid chromatography (HPLC). Erythrocytes from PNP-deficient patients contain a significant amount of deoxyGTP, which is not present in erythrocytes from either normal controls or ADA-deficient patients (Fig. 2). In contrast, erythrocytes from ADAdeficient patients contain deoxyATP, which is not present in either normal controls or PNP-deficient erythrocytes (10) (Fig. 2).

The concentrations of nucleoside triphosphates in erythrocytes from normal controls, ADA-deficient, PNP-deficient, and HGPRT-deficient patients are summarized in Table I. deoxyGTP levels are more than 10-fold higher in erythrocyte extracts from the two PNP-deficient patients, compared to the other controls and patients. While the ATP levels of all the extracts tested are comparable, guanosine triphosphate (GTP) concentrations are two-four times lower in extracts from either PNP-deficient or HGPRT-deficient patients, compared to normal controls. This decrease in GTP concentration is presumably the result of impaired guanine salvage capability caused by the absence of either PNP or HGPRT; however, other mechanisms are certainly possible.

To confirm the presence of deoxyGTP in PNPdeficient erythrocytes, we assayed deoxyGTP in the 


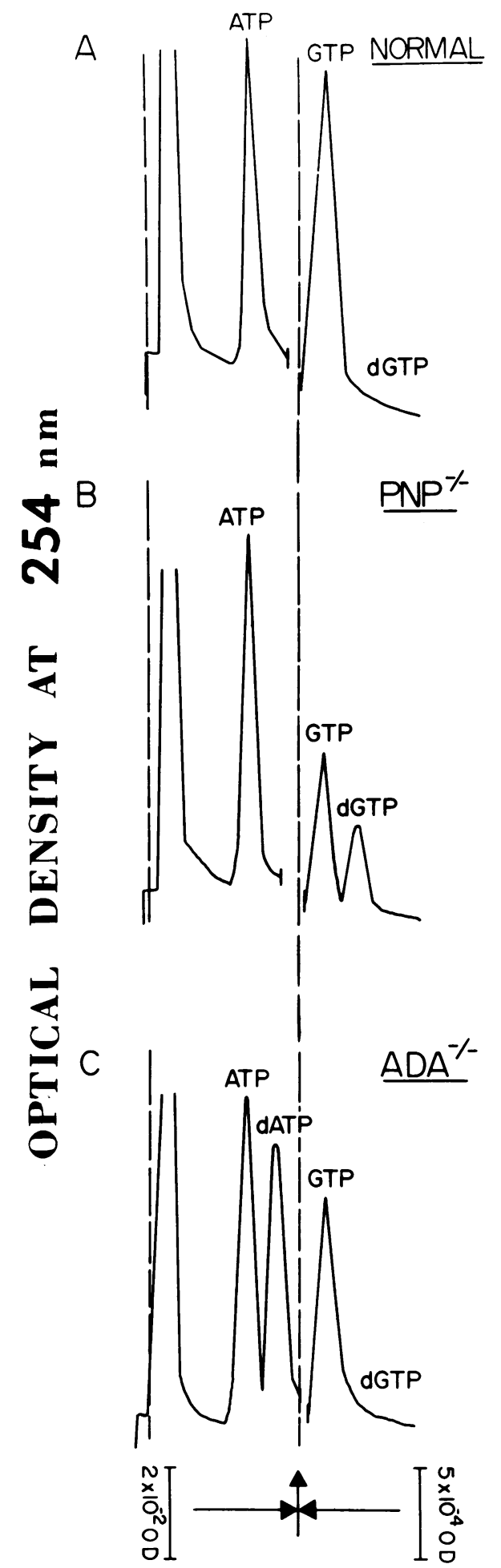

Figure 2 HPLC of nucleoside triphosphates in erythrocytes of normal controls, and PNP- (PNP-/-) and ADA(ADA-/-) deficient patients. Aliquots $(100 \mu \mathrm{l})$ of neutralized perchloric acid extracts of erythrocytes were applied to a Whatman Partisil 10-SAX column (Whatman, Inc., Clifton,
TABLE I

Ribonucleoside-Triphosphate and DeoxyribonucleosideTriphosphate Concentrations in Erythrocyte Extracts from Controls, PNP-, ADA-, and HGPRTDeficient Patients

\begin{tabular}{lcccc}
\hline \multicolumn{1}{c}{ Subjects } & ATP & dATP & GTP & dGTP \\
\hline & \multicolumn{3}{c}{ nmol/ml packed erythrocytes } \\
Controls & $1,150 \pm 100$ & $<20$ & $74 \pm 20$ & $<0.5$ \\
$\begin{array}{l}\text { PNP-deficient } \\
\quad \text { (patient 1) }\end{array}$ & 1,260 & $<20$ & 26 & 5 \\
$\begin{array}{l}\text { PNP-deficient } \\
\quad(\text { patient 2) }\end{array}$ & 1,320 & $<20$ & 19 & 8 \\
ADA-deficient & 1,100 & 1,100 & 60 & $<0.5$ \\
HGPRT-deficient & 1,080 & $<20$ & 32 & $<0.5$ \\
\hline
\end{tabular}

The values were determined by high-performance liquid chromatography as described in the legend to Fig. 1 and in Methods. The control values are averages of seven samples including five normal children and adults, and two immunodeficient children with nucleoside triphosphate concentrations indistinguishable from the normal controls. The values recorded for the enzyme-deficient patients are means of independent duplicates which differed by less than $8 \%$.

extracts from both PNP-deficient patients and normal controls with the DNA-dependent DNA polymerase reaction (15). The results obtained by HPLC and by the DNA polymerase assay agree. The control extracts contain deoxyGTP at a concentration of less than 0.5 $\mathrm{nmol} / \mathrm{ml}$ of packed erythrocytes, but the erythrocytes from PNP-deficient patients 1 and 2 contained 7 and 10 nmol of deoxyGTP/ml of packed erythrocytes, respectively, by the DNA polymerase assay.

\section{DISCUSSION}

deoxyGTP is synthesized in mammalian cells either via the reduction of guanosine diphosphate by ribonucleotide reductase (11), or by phosphorylation of deoxyguanosine (16). Since nondividing cells do not have ribonucleotide reductase activity (17), the phosphorylation route is the source of deoxyGTP in the erythrocytes from PNP-deficient patients. PNP-deficient patients cannot degrade deoxyguanosine, and thus, deoxyguanosine can either be phosphorylated to deoxyGTP or secreted in the urine of these pa-

N. J.) and eluted with $0.4 \mathrm{M}$ potassium phosphate, $\mathrm{pH}$ 3.6 , at a flow rate of $1 \mathrm{ml} / \mathrm{min}$. These tracings represent the 254-nm absorbance profiles of the eluted ATP, deoxyATP, GTP, and deoxyGTP. The sample injection points are indicated by the left-most broken vertical line. Relatively low sensitivity $(0.02 \mathrm{OD} / \mathrm{cm})$ was used to detect ATP and deoxyATP, while high sensitivity $(0.0005 \mathrm{OD} / \mathrm{cm})$ was used to detect GTP and deoxyGTP. The retention times of ATP, deoxyATP, GTP, and deoxyGTP were 18, 24, 31, and 37 min, respectively. 
tients, or both. PNP-deficient patients do secrete large amounts of deoxyguanosine in their urine (12). We now have evidence that children who lack PNP also accumulate an excess of deoxyGTP in their erythrocytes. Since deoxyGTP is a known inhibitor of cytidine diphosphate reduction in mammalian cells and promotes the reduction of ADP (11), the accumulation of high levels of deoxyGTP in dividing cells probably causes deprivation of deoxyCTP and thereby inhibits DNA synthesis. Although the levels of deoxynucleotides in normal erythrocytes are not detectable, studies with S49 mouse T-lymphoma cells in culture have demonstrated that these cells are starved for deoxyCTP after incubation in the presence of deoxyguanosine. ${ }^{2}$

It is conceivable that abnormally high levels of deoxyGTP accumulate in the T lymphocytes of PNPdeficient children and cause the observed T-lymphocyte killing. Since T lymphocytes are absent in PNPdeficient patients, it is not possible to measure deoxyGTP pools directly in these cells. However, it is intriguing that the thymus has the highest activity of deoxycytidine kinase (18), which also phosphorylates deoxyguanosine (16). ${ }^{2}$ Moreover, of the human fetal tissues examined by Carson et al., the thymus and spleen exhibit the highest deoxyguanosine phosphorylating activity (19). Thus, in the PNP-deficient patients, these tissues would be expected to have even higher deoxyGTP levels than do their erythrocytes. These observations can explain the tissue specificity of PNP deficiency because elevated deoxyGTP levels and the resulting cytotoxicity should correlate with deoxyguanosine phosphorylation.

This hypothesis also explains the clinical similarities in the ADA- and PNP-deficient, immunodeficient patients; a deficiency in ADA results in failure to degrade deoxyadenosine which is then phosphorylated to deoxyATP $(10,13)$, and a deficiency in PNP leads to an accumulation of deoxyguanosine which is phosphorylated to deoxyGTP $(13,16)$. In both types of enzyme deficiencies, the accumulation of the phosphorylated deoxyribonucleoside could cause the inhibition of ribonucleotide reductase, subsequent deoxynucleoside triphosphate starvation, and inhibition of DNA synthesis. The differences in the phenotypes of ADA- and PNP-deficient patients may be understood when more is known about the tissue distributions of specific kinase activities.

Finally, human lymphoid tissues can phosphorylate all four deoxynucleosides (13). Thus, a possible therapy for both ADA and PNP deficiencies would be ad-

\footnotetext{
${ }^{2}$ Gudas, L. J., B. Ullman, A. Cohen, and D. W. Martin, Jr. 1978. Deoxyguanosine toxicity in cultured lymphocytes and its relationship to purine nucleoside deficiency and the associated immunodeficiency disease. Submitted for publication.
}

ministration of the deoxynucleosides, particularly deoxycytidine, the triphosphates of which are depleted in these tissues. Deoxycytidine is not toxic in a number of model systems, ${ }^{2}$ and in fact, deoxyCTP does not appear to play a role in the allosteric regulation of ribonucleotide reductase $(11,20)$.

\section{ACKNOWLEDGMENTS}

This work was supported by a Center for Medical Genetics grant from the National Institute of General Medical Sciences, National Institutes of Health, U. S. Public Health Service.

\section{REFERENCES}

1. Giblett, E. L., J. E. Anderson, F. Cohen, B. Pollara, and H. J. Meuwissen. 1972. Adenosine deaminase deficiency in two patients with severely impaired cellular immunity. Lancet. II: 1067-1069.

2. Giblett, E. L., A. J. Ammann, D. W. Wara, R. Sandman, and L. K. Diamond. 1975. Nucleoside phosphorylase deficiency in a child with severely defective T-cell immunity and normal B-cell immunity. Lancet. I: 1010-1013.

3. Green, H., and T. S. Chan. 1973. Pyrimidine starvation induced by adenosine in fibroblasts and lymphoid cells: role of adenosine deaminase. Science (Wash. D. C.). 182: 836-837.

4. Wolberg, G., T. P. Zimmerman, K. Hiemstra, M. Winston, and L. C. Chu. 1975. Adenosine inhibition of lymphocytemediated cytolysis: possible role of cyclic adenosine monophosphate. Science (Wash. D. C.). 187: 957-959.

5. Kredich, N. M., and D. W. Martin, Jr. 1977. Role of Sadenosylhomocysteine in adenosine mediated toxicity in cultured mouse T lymphoma cells. Cell. 12: 931-938.

6. Agarwal, R. P., G. W. Crabtree, R. E. Parks, Jr., J. A. Nelson, R. Keightley, R. Parkman, F. S. Rosen, R. C. Stern, and S. H. Polmar. 1976. Purine nucleoside metabolism in the erythrocytes of patients with adenosine deaminase deficiency and severe combined immunodeficiency. J. Clin. Invest. 57: 1025-1035.

7. Gudas, L. J., A. Cohen, B. Ullman, and D. W. Martin, Jr. 1978. Analysis of adenosine mediated pyrimidine starvation using cultured wild type and mutant mouse $\mathrm{T}$ lymphoma cells. Somatic Cell Genetics. In press.

8. Ullman, B., A. Cohen, and D. W. Martin, Jr. 1976. Characterization of a cell culture model for the study of adenosine deaminase and purine nucleoside phosphorylase-deficient immunologic disease. Cell. 9: 205-211.

9. Cohen, A., G. E. J. Staal, A. J. Ammann, and D. W. Martin, Jr. 1977. Orotic aciduria in two unrelated patients with inherited deficiencies of purine nucleoside phòsphorylase. J. Clin. Invest. 60:491-494.

10. Cohen, A., R. Hirschhorn, S. D. Horowitz, A. Rubinstein, S. H. Polmar, R. Hong, and D. W. Martin, Jr. 1978. Deoxyadenosine triphosphate as a potentially toxic metabolite in adenosine deaminase deficiency. Proc. Natl. Acad. Sci. U. S. A. 75: 472-476.

11. Moore, E. C., and R. B. Hurlbert. 1966. Regulation of mammalian deoxyribonucleotide biosynthesis by nucleotide or activators and inhibitors. J. Biol. Chem. 241: 4802-4809.

12. Cohen, A., D. Doyle, D. W. Martin, Jr., and A. J. Ammann. 
1976. Abnormal purine metabolism and purine overproduction in a patient deficient in purine nucleoside phosphorylase. N. Engl. J. Med. 295: 1449-1454.

13. Tattersall, M. H., K. Ganeshaguru, and A. V. Hoffbrand. 1975. The effect of external deoxyribonucleosides on deoxyribonucleoside triphosphate concentrations in human lymphocytes. Biochem. Pharmacol. 24:1495-1498.

14. Stoop, J. W., B. J. M. Zegers, G. F. M. Hendrickx, L. H. Siegenbeek van Heukelom, G. E. J. Staal, P. K. de Bree, S. K. Wadman, and R. E. Ballieux. 1977. Purine nucleoside phosphorylase deficiency and cellular immunodeficiency. N. Engl. J. Med. 296: 651-655.

15. Solter, A. W., and R. E. Handschumacher. 1969. A rapid quantitative determination of deoxyribonucleoside triphosphates based on the enzymatic synthesis of DNA. Biochim. Biophys. Acta. 174: 585-590.

16. Krenitsky, T. A., J. V. Tuttle, G. W. Koszalka, I. S. Chen, L. Beacham, J. L. Rideout, and G. B. Elion. 1976. Deoxy- cytidine kinase from calf thymus. J. Biol. Chem. 51: 4055-4061.

17. Naudenskjold, B. A., L. Skoag, N. C. Brown, and P. Reichard. 1970. Deoxyribonucleotide pools and deoxyribonucleic acid synthesis in cultured mouse embryo cells. J. Biol. Chem. 245: 5360-5368.

18. Durham, J. P., and D. H. Ives. 1969. Deoxycytidine kinase. 1. Distribution in normal and neoplastic tissues and interrelationships of deoxycytidine and 1- $\beta$-Darabinofuranosylcytosine phosphorylation. Mol. Pharmacol. 5: 358-375.

19. Carson, D. A., J. Kaye, and J. E. Seegmiller. 1977. Lymphospecific toxicity in adenosine deaminase deficiency and purine nucleoside phosphorylase deficiency: Possible role of nucleoside kinase(s). Proc. Natl. Acad. Sci. U. S. A. 74: 5677-5681.

20. Reichard, P. 1978. From deoxynucleotides to DNA synthesis. Fed. Proc. 37: 9-14. 